\title{
Chapter 3 \\ Providing Outdoor Experiences for Infants and Toddlers: Pedagogical Possibilities and Challenges from a Brazilian Early Childhood Education Centre Case Study
}

\author{
Natália Meireles Santos da Costa, Maria Clotilde Rossetti-Ferreira, \\ and Ana Maria de Araujo Mello
}

\begin{abstract}
Intense urbanization process in Brazil and Latin America has increasingly limited young children, since birth, to access outdoor spaces, especially green areas. Moreover, as conceptions of babies in domestic care support confinement practices, apprehending infants' constitutive specificities as being intertwined with broader socio-cultural contexts requires further investigation. Notwithstanding the challenges, Early Childhood Education and Care (ECEC) institutions can be promising places to provide babies with daily contacts and appropriation of external areas amid an expanded collective experience. This chapter tackles the process of insertion and appropriation of outdoor spaces for infants and toddlers. We bring a case study from a Brazilian daycare centre with planned multiple outdoor environments, diversified spatial arrangements and natural elements. The empirical material, referring to the transition year of a group of under-twos, includes monthly recordings of everyday routine, interviews, field notes, institutional documents. We describe and analyze various outdoor spaces and socio-spatial practices of the daycare centre based on the cultural-historical perspective of the Network of Meanings. In the first semester, environments organized in semi-open areas connected to closed spaces were more frequently used. Whereas mainly in the second semester, given walking onset and greater motor resourcefulness, the going and appropriation of green areas unfolded as a gradual process not short of struggles. Substantial planning, projects and educational situations put forward by multiple social actors within a multidisciplinary approach modulated alternation of spaces and facilitated exchanges with peers, older children and adults - including family members.
\end{abstract}

The original version of this chapter was revised: Acknowledgement has been included at the end of the chapter. The correction to this chapter is available at https://doi.org/10.1007/978-3-03072595-2_12

N. M. S. da Costa $(\bowtie) \cdot$ M. C. Rossetti-Ferreira · A. M. d. A. Mello

CINDEDI (Centre for Research on Human Development and Early Childhood Education),

University of São Paulo, São Paulo, Brazil

e-mail: nmeireles@usp.br; mcrferre@usp.br; anam@alumni.usp.br

(C) The Author(s) 2021, corrected publication 2021

L. T. Grindheim et al. (eds.), Outdoor Learning and Play,

International Perspectives on Early Childhood Education and Development 34,

https://doi.org/10.1007/978-3-030-72595-2_3 
Keywords Outdoor environment $\cdot$ ECEC $\cdot$ Infant-toddler $\cdot$ Socio-spatial experiences

\subsection{Urbanization in Latin America and Children's Access to Outdoors}

Brazil is a tropical country of continental dimensions, being the largest in Latin America and occupying nearly half of South America. It has an extensive coastal area and spans several climatic zones and biomes. The total population is estimated at 211.755.692 inhabitants (IBGE, 2019) that are heterogeneously distributed across 26 states and the federal district. The Southeast region comprises $42 \%$ of the population and is composed of four states, among which São Paulo stands out as the most populous $(45,919,049$ inhabitants), most demographically dense (166.23 inhabitants $/ \mathrm{km}^{2}$ ) and most urbanized one.

Following Latin America's historical trend, Brazil underwent intense industrial and urban sprawl, starting mainly from the 40s/50s (Rossetti-Ferreira, Ramon, \& Barreto, 2002). Currently, $89 \%$ of the population lives in urban areas where medium and large cities prevail, and constructions and vehicle traffic are prioritized in the urban scenery, hindering social life in open areas and contact with the natural landscape (Montero, García, \& Francesa, 2017).

In this panorama, the population struggles with unequal opportunities of access to green areas and high-quality public spaces in their daily lives, as these are distributed irregularly in cities and mostly concentrated in upper-class zones. Also, in the logic of the real estate market, gardens and green areas are usually restricted to residencies and private properties, where people of higher income enjoy exclusive use of them (Montero et al., 2017). Therefore, the issue of access to external spaces tackles the historical challenges of structural socio-economic inequality.

As participants of a socio-historical matrix (Rossetti-Ferreira, Amorim, \& Silva, 2007), the present scenario affects the (in)accessibility of children to external areas and nature (Dowdell, Gray, \& Malone, 2011), so that despite all environmental and climatic wealth and nature-related cultural heritage, younger generations in Brazil experience ever declining time outdoors. In the case of babies, their absence becomes socially naturalized. Due to crystalized adult-centred socio-cultural, concepts and confinement practices "privatize" infants to the domestic environment and shuns them away from mainstream research and public policy agendas (Silva \& Neves, 2020). Henceforth, not only practices intensify children's confinement, especially those under the age of two, but also the field lacks investigations that discuss outdoor provision for this age group (Kemp \& Josephidou, 2020; Kernan \& Devine, 2010; Tiriba \& Barros, 2018). Moreover, infants' social life becomes restricted to child-specific "islands" (Kernan \& Devine, 2010), such as homes, leisure centres or even institutions, where spatial clusters and "relational asepsis" may separate children from the outdoors and everyday life in society. 
Nonetheless, as "the context is (...) a constituent component of the very fabric of development" (Andenæs, 2011, p. 51), due to their collective and educationallyintentional nature, Early Childhood Education and Care (ECEC) settings and their socio-spatial practices stand out as promising research sites. Such contexts unveil the social world of children and the many personal, political and social issues related to childhood, such as values, rules, symbols of culture and ideology present in the subtlety of everyday life (Rutanen, 2012). Hence, ECEC centres, notably those articulated with public stances, hold the remarkable potential to foster children' cultural formation and identity as integrated to a social group, a territory and an ecosystem by promoting connection with the local community and articulating spaces as networks within an expanded coexistence (Kernan \& Devine, 2010).

However, even ECEC settings may fall short of outdoor provision due to a series of structural challenges. In Brazil, despite the historical endeavour of constructing national legislation and guidelines that legitimize the importance of outdoor spaces (Brasil \& COEDI, 2006; Tiriba \& Barros, 2018), a significant portion of ECEC units suffer from precarious infrastructure and maintenance, being unable to offer natural and open-air environments of quality. Moreover, these spaces are devalued in pedagogical practice and overshadowed by the adult-centric schooling and cognitive learning model, which: separates thinking from the body; channels practices, routines and institutional time according to this logic; favours children's confinement; and, narrows down access to external spaces mostly to moments of recreation, purposeless leisure, or transitional breaks (Tiriba \& Barros, 2018).

\subsection{Research Question and Objective}

Therefore, a starting point lies in promoting opportunities for action in safe, instigating and children-orientated spaces, notably gregarious and natural ones in our view. Thus, in this chapter we pose as our research question, how can outdoor spaces be afforded by infants and toddlers (under-twos) within pedagogical conceptions, practices and contexts? More specifically, how, when and which outdoor spaces could babies access, occupy and participate in their everyday experiences in collective educational settings, and how does pedagogical practice constrain the process?

Specifically, as our aim in this chapter, we seek to investigate the possibilities of access, occupation and participation of under-two babies in outdoor spaces within the pedagogical work of a Brazilian ECEC centre. To this end, we will discuss how these elements constrain infants` and toddlers experiences and appropriation of different spaces. This leads us to our theoretical approach.

\subsection{Theoretical Approach}

Network of meanings, educational space and the autonomous embodied baby. 
The perspective of the Network of Meanings (Rossetti-Ferreira et al., 2007) is a theoretical methodological tool that has been constituted from a historical dialogue between theory, research and praxis originally from developmental studies of young children in early childhood education settings. Based on cultural-historical authors such as Vygotsky, Wallon, Valsiner and Bakhtin, we conceptualize development as a process temporally (co)constructed by active people in specific scenarios that are culturally and socially situated.

Such conceptualization causes the researcher's focus to shift from the individual viewpoint to people and groups in interaction, their interdependence, synergy, negotiations, conflicts, and mutual constitution. The phenomena are observed through the lens of a processual view in naturalistic contexts, with attention to the persistence and/or transformation of elements that, jointly, contribute to reconstructing developmental trajectories within an ecological reality. This foregrounds the intimate and reciprocal constitution between person and context through the experiences that unfold (Rossetti-Ferreira et al., 2007; Vygotsky, 1934, 2010).

In this person-context intertwining, the environment is apprehended and appropriated differently according to children's specific developmental condition and their sensory, motor, perceptual and symbolic organizations (Carvalho, Pedrosa, \& Rossetti-Ferreira, 2012; Vygotsky, 1934, 2010) that become materialized in the concreteness of the society-nature relationship inserted a socio-historical matrix. Therefore, the environment is not the same at all ages, and it affords differing motivations, affective states, developmental stages and socio-cultural materiality for children. As the child's experience constitutes an inseparable unity with the meanings that are elaborated in the process, while children change throughout their development, the environment acquires new meanings according to their experiences and interpretations attributed socially, affecting and constituting dialectically the person-context unity (Vygostky, 1934; Vygotsky, 2010).

In view of the person-context unity, when it comes to ECEC contexts, the conceptualization and role of space becomes central. We define space as a curricular element, often referred to as the "third educator", which, in addition to its physical delimitation, is the place where life happens (Forneiro, 1998). For children, space is what they experience, feel and do within its contours, where meanings emerge and constitute the experiences that are unveiled there. Though space and environment may be used equivalently, here they are conceptually distinct. The physical space relates to the places where educational situations are developed, whereas the environment comprises the various objects, shapes, colours, aromas and people that inhabit and relate within the delimitation of the physical structure, as an inseparable whole.

Therefore, the environment is dynamic, lively, and embraces all these pulsating elements, constituting four interrelated dimensions: physical space - refers to concrete and organizational aspects; temporal - refers to the times and rhythms of use, including historical time, routine, and contrasting individual pacing; functional refers to the mode and purpose of use; and, relational - refers to the people, circumstances, possible interactions and norms of use (Forneiro, 1998). In the triple logic of space - environment - place, the environment is the locus of experience, where the mediating adult, who knows and presents the objects of culture, brings the child closer to a place (Moreira, 2013). 
As free movement and the autonomy of the child are starting points to this end, we should consider infants' developmental specificities, their organization and competence for social life, their possibilities for action and apprehension of the world according to what they can perceive and do with their bodies and their ability to affect and be affected by the others. Seeking to integrate these elements, we work with the notion of "embodiment" which is an instance of inseparable complementarity between the physical concreteness of the body and its experiences through active engagement with the world and others (Overton, 2008). In a dialogical relationship, the body signifies and is signified, expressed through tonicity, postures, gestures, movements of approaching or distancing, among other actions (Amorim \& Rossetti-Ferreira, 2008) that allow the baby to play different roles and connect in an intercorporeal relationship.

As a rapidly-changing process, infants` relationship with the environment through embodiment changes drastically in a matter of months. In the first two years of life, it is estimated that their height doubles, the bodyweight nearly quadruples and the circumference of the head increases by about a third (Adolph, 2008). Mobility gradually develops along with postural progression from the supine position until upright posture alongside the development of expanded gestures and movements that require increased balance, coordination, strength and speed. All these elements entail key transformations of perceptual-bodily possibilities and strategies, as well as the meanings attributed to infants, the places where they are taken to, how they are positioned, and how, in turn, they may embrace or conflict these (pro)positions (Amorim \& Rossetti-Ferreira, 2008).

These aspects draw attention to the practitioners`challenge of preparing environments in their functional, spatial, temporal and interactional dimensions (Forneiro, 1998) so that infants may act, express themselves, dialogue with various social actors and thus exercise their fundamental rights of participating in society (Coutinho \& Vieira, 2020). In counterpoint, we as researchers and scientific toolmakers (Holzman \& Newman, 1993) must take an active role in our relationship with the researched events and subjects, by building and making use of epistemological and methodological constructs that will amplify infants`action and standpoint. In our immersion in this effort, there are constant "zooming in" and "zooming out" analytical movements, in which epistemological premises channel elements and interpretations to the observed events (Rossetti-Ferreira et al., 2007) that may stand out as "figure", while others remain in the "background" as a network formation, always as a selection from a greater whole. Given these issues, we then present the construction of our methodological outline.

\subsection{Methodology}

We bring a qualitative case study (Rey, 2020; Yin, 2009) of a government-funded daycare centre in a medium-sized city in the state of São Paulo. The local Ethics Committee authorized the research, a partnership was established with the institution, and the participants granted their consent. Our unit of analysis (Matusov, 2007) 
in this chapter was the pedagogical situations in outdoor spaces developed throughout the year.

The study followed the first year of full-time attendance of a group of infants and toddlers, internally subdivided into two groups according to age. Throughout the first semester, both remained in the nursery module, but given the difference in development, the group of toddlers was moved to a different sector from the second semester onwards. Henceforth, our records shall focus mainly on the younger group, comprising six infants ( 3 boys and 3 girls, initial age from 7 months to 12 months).

The follow-up was monthly and longitudinal, throughout the school year, according to the Brazilian calendar. Observational material comprises naturalistic observations, video recordings and field notes that sought to accompany moments of routine (sleep, food, bath, exchange), moments of play, and moments of interaction throughout the period of stay. For the present work, we selected only the material related to the presence of infants in outdoor spaces.

In addition to this material, the daycare centre generously granted us images from its own collection along with class reports, written by the teachers, to further detail the pedagogical actions regarding the use of outdoors. Finally, we collected informal accounts from the teachers and prominent people involved in the history of conceiving and constructing the centre, so that the previously mentioned records contemplated the pedagogical intentionality intertwined with the practices.

From the triangulation of this material, we identified all the records that presented the infant group in outdoor spaces and organized them chronologically to investigate whether their use occurred in everyday life, and if, over time, additional spaces were included in the group's routine. In our analysis, we initially present the centre and its outdoor spatial configuration. Next, by organizing such records and reports temporally and thematically, we developed pedagogical narratives (Coutinho $\&$ Vieira, 2020) seeking to apprehend which outdoor spaces were most commonly accessed routinely, what were the possibilities of using these spaces beyond teachers` routine practice and whether/which new outdoor spaces were introduced over time. Henceforth, we will proceed to the presentation of the case and discuss our findings.

\subsection{Results and Discussion}

Our case study is of a publicly funded daycare centre that was built in a farm of $8000 \mathrm{~m} 2$, in the outskirts of town. The original building functioned as a silkworms rearing house, which was later transformed into the Rural School Group, and finally into a daycare centre. This educational space, therefore, was surrounded by large outdoor areas, abounding with grass, fruit trees and allowing broad contact with nature.

In the centre's historical process, spatial conception and structuring received influence from the pedagogy of authors such as Anísio Teixeira, Celéstin Freinet and Daniel Élkonin, who based on scientific progress of children's psychology from 

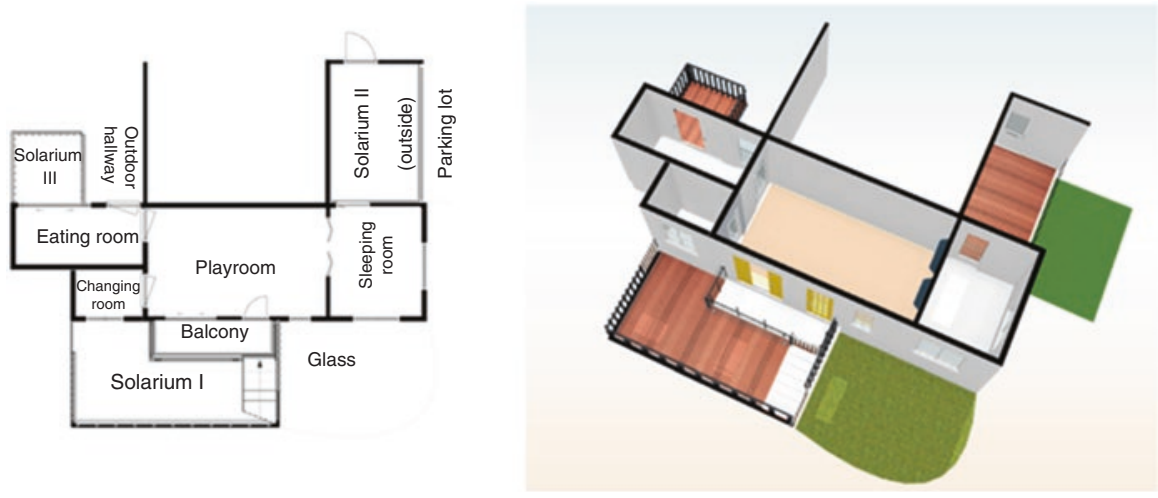

Fig. 3.1 Visual representation of the nursery complex

their time, advocated for greater freedom and autonomy for children. Also, relying on studies of environmental psychology, child development and education (RossettiFerreira, Oliveira, Campos-de-Carvalho, \& Amorim, 2010) institutional training oriented teachers' practice of (re)creating barriers and spatial geometry that could facilitate children's visual access of objects and same-age peers and foster greater participation, autonomy and spontaneous grouping. The centre was organized in sectors according to age groups and purpose and here we will focus on the external spaces that were intended for babies, notably those attached to the nursery complex and the wider outdoors.

The nursery complex, illustrated in Fig. 3.1, was composed of a variety of internal and external spaces, some equipped for care routine (bathing, eating, sleeping) and others structured for moments of interaction and play. The inner playroom had a seamless and unrestricted access to a balcony, providing outdoor-indoor connectedness (Kernan \& Devine, 2010), and had intermediate access to the other boundaried outdoor spaces (Kernan \& Devine, ibid) attached to the nursery complex, requiring passage through indoor spaces, with midway obstruction of baby gates on the doors. There was also a large solarium, which was accessed via a ramp attached to the balcony of the main hall, also obstructed by a short gate. As part of the pedagogical strategies, these attached external spaces were daily used in rotation and other spaces were gradually introduced into the babies' routine, though some should require more or less planning ahead.

There was a vast diversity of open spaces in the wider outdoors, a part composed by a complex of concrete areas and other part with several spaces in the green areas such as plazas, tables, houses, sand tanks, etc. Although groups more commonly used certain areas according to their age group and development conditions, the daycare centre sought to promote the occupation and participation of everyone in the different spaces. For this, teachers and a technical team (with pedagogical coordinators, psychologist, nutrition and nursing technician) engaged in recurrent planning and sought to integrate proposals more particularly focused on infants, their skills, challenges and needs. 
In terms of socio-spatial practices (Rutanen, 2012), we observed that not all outdoor areas were accessed equally from the start. During the first semester, the infants' group would mostly be limited to the nusery's attached spaces (indooroutdoor connectedness and boundaried outdoor spaces). We also observed that the centre created opportunities for these and wider spaces to be accessed on alternative periods, where more adults could be present. Finally, that children's developed recurrent going to wider outdoor areas upon cruising and walking onset, which happened mainly in the second semester.

Therefore, we organize narratives of these practices in a temporal logic within the following strands of analysis: "attached outdoor spaces as part of everyday life", "projects, workshops and the diversification of spaces" and "paving the way for the wider (green and concrete) areas". In each of these strands, we discuss the possibility of infants' access, the pedagogical propositions developed, and the infants' actions regarding these propositions, seeking to discuss how the intertwining of these elements constitute infants' cultural formation within the outdoors (Hedegaard \& Ødegaard, 2020; Rossetti-Ferreira et al., 2007). Therefore, we shall proceed to these strands of analysis.

\subsubsection{Attached Outdoor Spaces as Part of Everyday Life}

We observed that, from day-one, the nursery's attached outdoor spaces were accessed on a daily basis. Because temporality is one of the dimensions of the environment (Forneiro, 1998) that alters the needs of children in this age group, the morning and afternoon periods had different temporal-spatial arrangements. The more structured outdoor spatial organizations were planned for moments of arrival, after lunch, after the afternoon nap and before departure.

In these moments, as a way of demarcating space and structuring an environment, the teachers spread out mats and large toys (e.g. activity centres, learning walkers, etc.) on the floor and hung objects (e.g. rattles, cloths, etc.) on the fences, within the children's reach. We interpreted this situation as an intentional invitation for babies to remain outside, as we identified several records in which they gathered in groups in that area and gradually stayed for a longer time, demonstrating increasing initiative to direct themselves and remain there. Also, the adult's practice of heading and staying outside were references of spatial orientation for babies and facilitated the formation of groups and fostered sustained engagement and sharing of attention/actions in educational situations (Campos-de-Carvalho, 2004; Musatti, Mayer, Pettenati, \& Picchio, 2017) Over time, we observed that the babies started to head outside autonomously more often, independently of the adult being present or not.

Besides the spatial organization previously described, teachers often (re)positioned the gates' barriers and recreated spatial geometry, since many of the passages from one space to another had support for fitting mobile grids, We observed that these spatial (re)arrangements (Campos-de-Carvalho, 2004) invited infants to 
experience and explore the same place differently and redirect their attention to specific features of space possibly unnoticed in their regular everyday use. For example, when teachers left the entry gate open and obstructed the corridor towards the solarium with a detachable gate, the ramp, usually a simple hallway, was transformed into a speeding "driveway" for car toys by children.

We also identified infants experiencing and appropriating the multiplicity of spatial dimensions (Forneiro, 1998) in everyday situations such as: contemplatng and interacting with the landscape and elements of nature nearby (e.g. wind, birds, trees, grass); playing with water using outdoor showers, basins and dolls (differing from the stationary posture and temporal configuration of bath routine); manipulating fluid matter, and getting dirty without restriction. Regarding the fences: toddlers threw objects beyond the gate and fence, or even tried handling the lock; cruising infants leaned on the fence and walked throughout its contours; and, infants had close or distal interaction with older children and adults who went by the corridors.

Therefore, we observed that access to external spaces was guaranteed from the beginning, became diversified over time and was legitimatized as pedagogical locus of infants' autonomy. Temporal-spatial arrays and the permanence of the adult were important elements to channel the direction and permanence of the babies. Also, practitioners had high concerns of carrying out the process gradually, respecting infants' habituation, rhythm and initiative so that they had physical and emotional security to explore such places. Finally, visual openness and postural accessibility through affordances (Gibson, 1979) (e.g. low gates and fences that afforded cruising support) fostered infants expansive and independent movement, whilst allowed extended contact with people and outer surroundings that composed a wider ecosystem, beyond the aseptic and adult-centric reference in a room.

Moreover, through the interrelationship of elements such as permeability/porosity, demarcation/flexibility, versatility/stability, and openness/containment constrained different ways of infants inserting themselves in attached outdoor spaces and integrating them into daily life as environments of exploration, discovery, and communication with the nursery's surroundings and community.

With greater habituation of babies to open-air environments, teachers began to conduct more structured actions in the nursery's attached outdoors and the wider areas, notably those which were more difficult to access on a daily basis. This occurred mainly from the proposal for projects and workshops, which shall be our following topic.

\subsubsection{Projects, Workshops and the Diversification of Spaces}

This ECEC unit conceived its relationship with families as a partnership and sought to establish a joint work in promoting the children's development and well-being. As a result, in addition to the practices regularly developed by the teachers, the centre promoted a series of educational situations, which were coordinated by different actors and often included families, notably through workshops and 
integrative projects (Barbosa \& Horn, 2009). We observed that most of these situations occurred in outdoor spaces.

Due to the proximity to parents' workplace, family members were invited to visit the centre during lunch hours and stay with their children during this period every day. Although this proposal initially sought to handle work shifts and favour a more gradual transition for full-time babies, visiting hours throughout the history of the daycare became a significant moment of integration between families and the centre community. During the visits parents often took infants to the green areas. On that occasion, they were able to have one-to-one interactions and meet more directly infants' individual interests by diversifying their access to spaces that would be difficult during group time, for requiring bodily handling and more individualized supervision (e.g. being pushed on the swing, exploring the playhouses, being carried in the lap to see the animals).

We also identified this diversification of access occurring in structured moments organized with parents. The reports mention musical recitals in the park plaza, children's birthday celebrations or craft workshops in the solariums or even at tables in the park, picnics and outdoor storytelling. Moreover, off-hours commemorative events also provided opportunities for families to circulate through the centre and enjoy their wider outdoor spaces in another setting. Hence, children were presented to and experienced a diversity of cultural arrays in the outdoors by having the necessary support to participate, express themselves and act on their interests, despite their momentary physical limitations. This all becomes fundamental in the process of transforming space in an environment, and children being invited to transform it into a place by active participation (Moreira, 2013).

Moreover, such elements proved to be potent incentives for children and their parents to experience a daily period outside with their children in a way that the experience could also be pleasant for adults, which according to Tiriba and Barros (2018) is an important step in the process of constituting experiences in the outdoors. Therefore, such opportunities also allowed parents, who are also part of this confinement ecosystem, to experience pleasant day-to-day moments with their children and come to value these types of space more.

In some of these visiting moments, the nursery's technical team held a series of sensorial workshops in which they presented sensory challenges to infants that could be freely manipulated and explored. The centre followed a plan for when and which substances would be (re)offered. These included wet and dry foods, such as cornmeal, sago, flour, objects in contrasting temperatures, fabrics of various textures, etc. It was a practice that allowed infants to experience the different sensations aroused by these elements, to help them to get used to being dirty, or even make their peers dirty. These expansive gestures, such as scattering, spilling and pinching gestures, were often newly experienced by babies by repeating several cycles of the same actions, which Henri Wallon, conceptualized as acquisition play, where the child observes using the full body, as if it were all eyes and all ears (Wallon, p. 76, 1981) (Fig. 3.2).

This was an important moment to prepare babies for the parks, where they would play with sand, mud, leaves, feel the texture of the grass and the dirt. For this reason, 

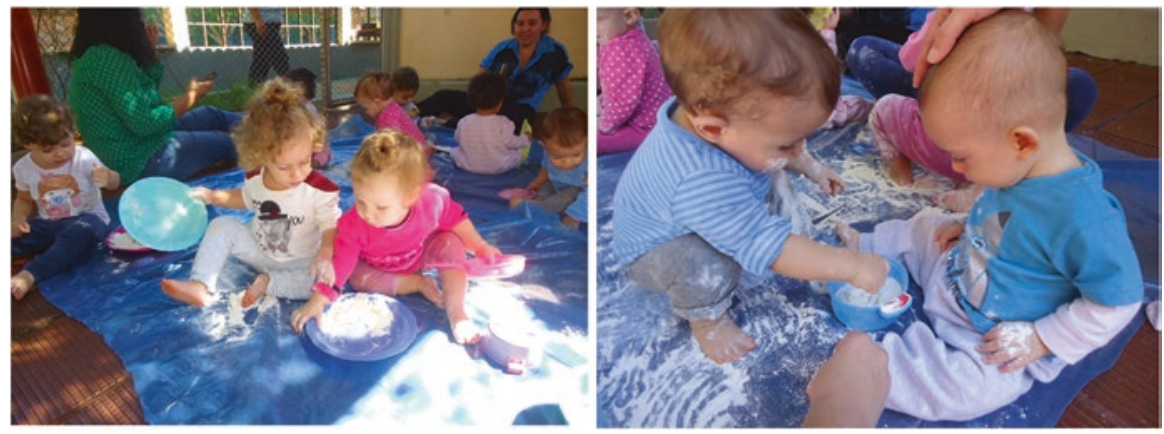

Fig. 3.2 Photos from the sensorial workshops

the teachers were attentive to the children's reactions, especially those of discomfort, monitoring if the discomfort persisted or not in following sessions. Moreover, this was an opportunity for parents to experience this way of playing with their children and encourage them to explore, or even comfort their refusals and possible difficulties.

Thus, in the flow of occupation of outdoor spaces, the next step was to take children to wider outdoors in a more autonomous manner. This process occurred mainly in the second semester and will be discussed in the next topic.

\subsubsection{Paving the Way for the Wider (Green and Concrete) Outdoor Areas}

The centre had two complexes of wider outdoors, each at opposite ends of the unit's grounds. The area closest to the lunch room was of concrete floor and comprised covered areas (e.g. semi-open patios and corridors), as well as open areas (e.g. sports court, areas with showers). The area closest to the large solarium/entrance ramp, on the other hand, gave access to the wider green areas, which were structured in delimited spaces such as plazas, sand tanks, various types of playhouses, bird coops, playgrounds etc. According to the teacher's report and mapping of the records, the younger group most recurrent trips to these places started to take place in the second semester. At this time, only the younger group had remained in the nursery and all babies had developed independent mobility with differing onsets (crawling, cruising and walking).

The key teacher tells us that these moments were challenging, required planning in advance, and eventually demanded help from an aid. Some babies needed to be carried/physically assisted, occasionally a child expressed discomfort or needed to return to the room (e.g. diaper accident) and there was a concern that babies did not disperse. Regarding weather events, because of the hot weather subject to mosquitoes-borne diseases, parents collectively provided sunscreen and repellent 
for children's daily use. Moreover, the maintenance of these spaces was costly and complex, requiring regular insect removal, gardening work, animal care, hygiene of toys and sand tanks, among other aspects.

However, notwithstanding the various challenges and requirements, the use of outdoor spaces was rooted and valued in the centre's pedagogical premise and practices. Access to the outdoors was embedded as fundamental rights of children (MEC, Brazil, 1995, 2009), that included the "right to movement in wide spaces" and "the right to contact with nature". These notions were historically built within intersectoral work and training of teachers and staff, so the centre could foster joint effort to help children make use and develop abilities that would allow them to exercise these rights. To demonstrate how access to the wider cemented and green areas took place, we selected two vignettes that will be discussed shortly.

The first vignette refers to the fifth month of attendance, in which the children's age varied between 12 months and 17 months and illustrates their going to the patio in the wider cemented outdoors. On that day, five of the babies were present (Fig. 3.3).

Inside the room, the teacher is near a small gate that interconnects the lunch area to an external corridor. Babies gather around her, some standing, some in crawling position. After the teacher puts on her shoes, she exclaims "let's go for a walk!" and immediately one of the babies heads towards a high wooden niche where his shoes are. He tiptoes on his feet trying to grab them, but is unable to reach his shoes. A few moments later, the teacher heads outside, and the babies (crawlers, novice and experienced walkers) follow her in line. The teacher goes down the corridor and turns left. At this turning point, a wider and more visually complex spatial field opens up for the babies (e.g, crossing corridors, access to doors and patios from other rooms and people circulating). With the exception of a walking baby who follows the teacher, all the other four interrupt their traveling and stay sit when they reach this point. The teacher kneels facing them, smiles and calls out "come, let's play!".

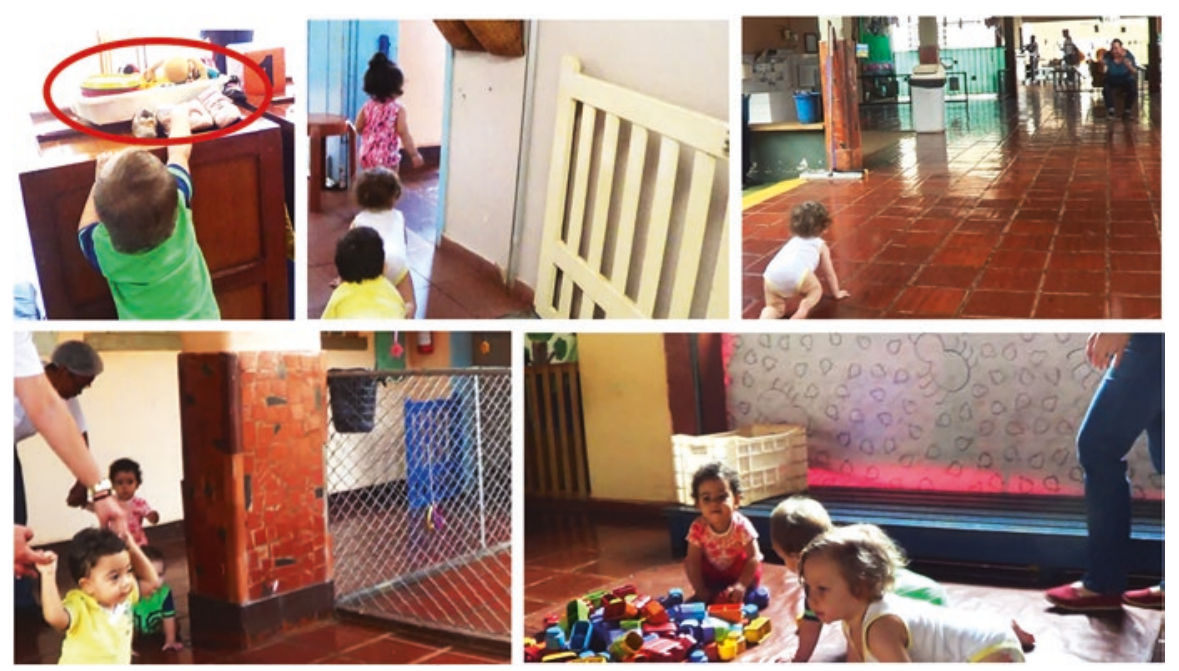

Fig. 3.3 The group heading to the patio 
One of the babies goes out on a crawling bout towards the teacher. The remaining babies stay in crawling position, gazing at the teacher and apparently struggling to move forward. Some employees around encourage the infants verbally and offer support for cruising, helping them stand and move forward. It takes nearly three minutes for all the babies to reach the teacher. When the group is complete, the teacher spreads out a rug on the floor and provides a box of toys for the children to play.

We highlight some points from this vignette. First, we observed that when grouping close to the little gate with the teacher and even reproducing cultural gestures through immediate and deferred imitation (Werebe \& Nadel-Brulfert, 1986), such as fetching the shoe, babies are able to anticipate the moment to leave and show signs of appropriation. A second point is that the difference in locomotor acquisitions integrates and constrains perception-action mechanisms in babies who move differently (Gibson, 1988). According to Kretch, Franchak \& Adolph (Kretch, Franchak, \& Adolph, 2014), walking babies have their visual flow and movement more easily targeted ahead, while crawling babies have their visual field more directed to the floor and need to sit and scan the environment to reach targets. This might be one of the reasons why at the corridor's turning point crawling infants struggle more to move forward, in contrast to the walking toddler.

Hence, the postural and locomotor aspects are central when considering the possibilities of infant's movement and displacement in wider outdoor space. This doesn't imply that babies were left to their devices. As they were able to take steps with cruising, their displacement was facilitated by receiving postural support from adults. Finally, not only the teacher, but other staff members were engaged in guiding babies to the patio, where they could be visible, perceptible while they could also see and perceive others.

The second vignette refers to the eighth month of attendance, with the children (who are now toddlers) ages ranging from 15 months to 21 months. On this day, there were six toddlers present (Fig. 3.4).
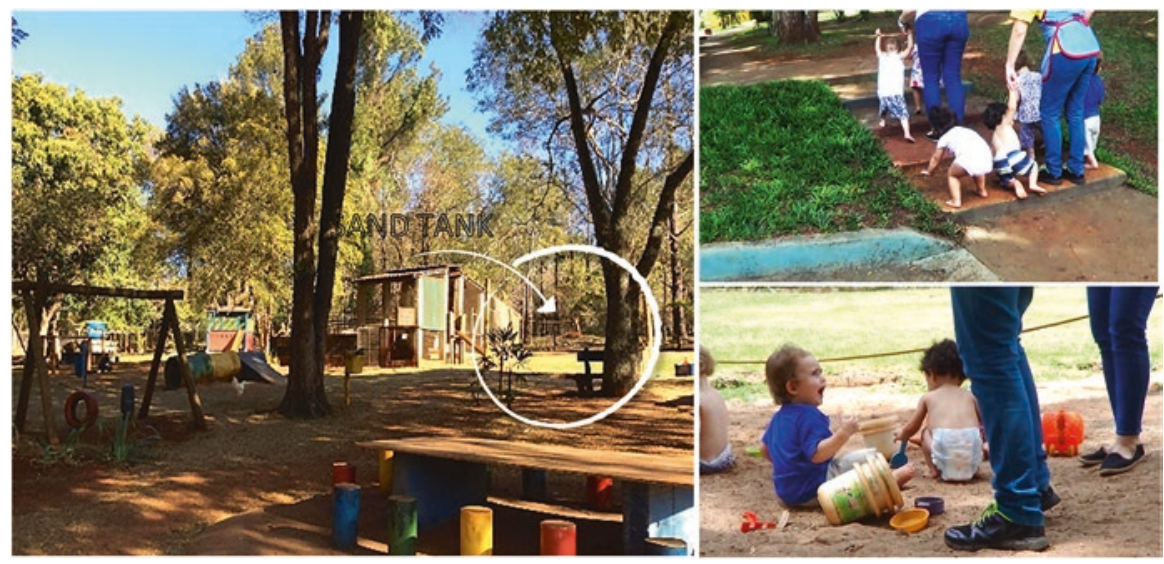

Fig. 3.4 The group heading to the sand tank in the green area 
The scene starts when the group of children, the main teacher and an auxiliary are moving from the semi-open corridor to the open green areas. All children can walk independently. There is a marked path on the ground that starts at the covered area and seamlessly extends to the park. Just upon entering the park, there is a broad and low stairway to facilitate small steps, but even so the toddlers struggle. In one scene, three stumble and fall at the same time (without getting hurt), placing their hands on the floor to absorb impact. One of the toddlers climbs up the remaining steps in this position (legs extended, torso bent forward and hands on the floor, also called "bear crawling"). The teacher and assistant reach out their hand and help the children who have to walk the remaining steps. Upon arriving at the park, the children begin to follow the paved path that passes by one of the play houses. The teacher and assistant, however, go right across the grass, heading towards the sand tank, and call the children. They say "sand, we're heading to the sand". Some toddlers follow them immediately, but others need to be called more insistently or led by hand. When everyone reaches the sand tank, the adults hand over buckets, water and sand tools. There is a scene in which one of the babies tries different ways of putting the sand into the bucket, first with the sieve, then with pinching hand gestures, and after looking around, says "pá.pá" (the word in Portuguese for shovel, which resembles one of the initial babbling babies' utterances). Shortly afterwards, the assistant hands over a shovel, which the baby uses to throw sand into the bucket.

In the excerpt, the marked path helped children to orient themselves, but the stairs and moving away from the path were challenges along the way. Apprehending the route and learning to walk either through a delimited path or open space with greater autonomy and confidence are embodied educational situations. Besides motricity issues, spatial and time use diverged between adults and children, in a way that infants and toddlers' processing and action time, both in gesture and in language, conflicted with the adult.

Due to such a distinction, times and directions needed to be (re)negotiated, requiring changes of rhythm, transmutation of space (Gobbi, Leite, \& Pito, 2019) and re-arrangement of locomotor aims. Within a structured proposal, such as playing in the sand, cultural artefacts instrumentalized the children's actions in their contact with reality, allowing them to experience different textures, dry or wet, and to explore different modes of handling. When transferring the sand to the bucket, for instance, by testing varied hand movements and experimenting with tools, children indicate a rudimentary apprehension of everyday concepts and learning through acquisition games (Wallon, 1981).

In view of the analyzes discussed, we will move on to the final considerations.

\subsection{Final Considerations}

Infants and toddlers face the challenge of having their access and participation to outdoor spaces denied or hindered, which permeate historical confinement practices, with cribs, containment devices, small rooms and nowadays, even restraining through media devices (Kopp, 2011). Allied to these issues, urban structuring, socio-economic inequalities and conceptions of care and education that favor confinement and adult-centric models perpetuate those practices. Despite the 
challenges, collective spaces, such as early childhood education units, have the great potential to ressignify those issues and actively contribute to their cultural formation on such matter.

Through the case, we identified that the structuring of spaces reflects expectations and meanings about what is desired in the pedagogical process. When practitioners intervene in space, by prior organization, by routine insertion, by physical demarcation, and by stimulus to the independent action of the child, they can offer children a safe and stimulating environment that provides experiences and gradual appropriation. In doing so, children can "activate the different modes of interaction with others and the environment depending on the situations they encounter and according to the means available in their behavioral repertoire and the goals they seek" (Wallon, 1942).

As "it takes a village to raise a child", the case also reveals the potential of including different actors in the daycare centre when planning actions and accompanying children in their moments in outdoor spaces. The possibility of bringing families into the centre and watching their children interacting with the outdoor environment on a daily basis contributes to the adult having a more qualified and attentive look to the way the child acts, its capacities and its challenges. The proposals for workshops and projects help to diversify the access and use of spaces, and contribute to the socialization and integration process of both children and families at the institution.

Finally, the infants' developmental resources constrain the way they are inserted and navigate through outdoor spaces. The possibility of adjoining areas closer to the rooms used by babies can facilitate their daily exposure to the outdoors and to venture into actions specifically provided by such places, in a more gradual and safe way. Also, the complexity of trips to wider outdoors, notably green areas, should be possibly considered as a pedagogical practice in itself, taking into account the differences in children's times and skills, with a distinction between those crawling, cruising and walking infants/toddlers.

Therefore, in agreement with Dowdell et al. (2011), we argue that access and exposure to nature and outdoor gregarious spaces allow babies and young children to exercise their rights and learn about the world with hands-on experience without needing adult-centered explanations, constituting their cultural formation (Hedegaard \& Ødegaard, 2020) as participants in both local and wider territories. Hence, confinement practices and centralization of the relationships around the adult's proposal are more easily dissolved in the outdoors, and even upon developmental limitations, adults can be supportive of children's initiative and activeness. In a triple protagonism, the child eager to learn and act is affected by the environment, and the teacher, who knows the cultural object, presents and draws the child closer towards it (Oliveira et al., 2012). To this end, it is essential to provide possibilities of access and occupation to reframe conceptions, practices and even policies related to babies and young children.

Acknowledgements We acknowledge support from CNPQ (Brazilian National Council for Scientific and Technological Development) and FAPESP. - Grant 2016/24466-7, São Paulo Research Foundation (FAPESP). 


\section{References}

Adolph, K. E. (2008). Learning to move. Current Directions in Psychological Science, 17(3), 213-218.

Amorim, K., \& Rossetti-Ferreira, M. C. (2008). Corporeidade, significação e o primeiro ano de vida. Arquivos Brasileiros de Psicologia, 60(1), 67-81.

Andenæs, A. (2011). Chains of care: Organising the everyday life of young children attending day care. Nordic Psychology, 63(2), 49.

Barbosa, M. C. S., \& Horn, M. D. G. S. (2009). Projetos pedagógicos na educação infantil. Porto Alegre, Brazil: Artmed.

Brasil, M., \& Coedi, S. (2006). Parâmetros nacionais de qualidade para a educação infantil. Brasília, Brazil: MEC/SEB.

Campos-de-Carvalho, M. (2004). Use of space by children in day care centers. Revista de Etologia, $6(1), 41-48$.

Carvalho, A. M., Pedrosa, M. I., \& Rossetti-Ferreira, M. C. (2012). Aprendendo com a criança de zero a seis anos (1st ed.). São Paulo, Brazil: Cortez.

Coutinho, A. S., \& Vieira, D. M. (2020). Uma perspectiva para acompanhar o processo dos bebês de conquista da autonomia na creche. Revista Interinstitucional Artes de Educar, 6(2), 602-626.

Dowdell, K., Gray, T., \& Malone, K. (2011). Nature and its influence on children's outdoor play. Journal of Outdoor and Environmental Education, 15(2), 24-35.

Forneiro, L. I. (1998). A organização dos espaços na educação infantil. In M. A. Zabalza (Ed.), Qualidade em educação infantil (B. A. Neves, Trans.). Porto Alegre, Brazil: Artmed.

Gibson, J. J. (1979). The Ecological Approach to Visual Perception. Boston, USA: Houghton Mifflin.

Gibson, E. J. (1988). Exploratory behavior in the development of perceiving, acting, and the acquiring of knowledge. Annual Review of Psychology, 39, 1-42.

Gobbi, Leite, \& Pito. (2019). Sociologia urbana e os bebês: (im)pertinentes, ou a silenciosa insurgência em crianças pequenas. Estudos de bebês e diálogos com a sociologia (1st ed.pp. 493-517). São Carlos, Brazil: Pedro \& João Editores.

Hedegaard, M., \& Ødegaard, E. E. (2020). Introduction to children's exploration and cultural formation. In M. Hedegaard \& E. E. Ødegaard (Eds.), Children's exploration and cultural formation (1st ed., pp. 1-10). Cham, Switzerland: Springer International Publishing.

Holzman, L., \& Newman, F. D. (1993). Lev Vygotsky: Revolutionary scientist. London: Routledge.

IBGE - Instituto Brasileiro de Geografia e Estatística. (2019). Available in: https://cidades.ibge. gov.br/brasil/panorama

Kemp, N., \& Josephidou, J. (2020). Where are the babies? Engaging the under twos with the outdoors. Canterbury, United Kingdom: The Froebel Trust.

Kernan, M., \& Devine, D. (2010). Being confined within? Constructions of the good childhood and outdoor play in early childhood education and care settings in Ireland. Children \& Society, 24(5), 371-385.

Kopp, C. B. (2011). Development in the early years: Socialization, motor development, and consciousness. Annual Review of Psychology, 62, 165-187.

Kretch, K. S., Franchak, J. M., \& Adolph, K. E. (2014). Crawling and walking infants see the world differently. Child Development, 85(4), 1503-1518.

Matusov, E. (2007). In search ofthe appropriate'unit of analysis for sociocultural research. Culture \& Psychology, 13(3), 307-333.

Montero, L., García, J., \& Francesa, C. R. (2017). Panorama multidimensional del desarrollo urbano en América Latina y el Caribe. Comisión Económica para América Latina y el Caribe (CEPAL). Published by the United Nations Organization. Available in: https://repositorio. cepal.org/handle/11362/41974

Moreira, A. R. C. P. (2013). Os bebês e os espaços da creche: um estudo de caso/intervenção. Revista de Educação Pública, 22(49/1), 305-325. 
Musatti, T., Mayer, S., Pettenati, P., \& Picchio, M. (2017). Toddlers' participation in joint activities with peers in nido. In E. J. White \& C. Dalli (Eds.), Under-three year olds in policy and practice (pp. 73-86). Singapore, Singapore: Springer.

Oliveira, Z. R. D., Maranhão, D., Abbud, I., Zurawski, M. P., Ferreira, M. V., \& Augusto, S. O. (2012). Planejar práticas pedagógicas: princípios e critérios. In Z. M. R. Oliveira, D. Maranhão, I. Abbud, M. P. Zurawski, M. V. Ferreira, \& S. O. Augusto (Eds.), O trabalho do professor na Educação Infantil (1st ed., pp. 37-56). Biruta.

Overton, W. F. (2008). Embodiment from a relational perspective. Developmental perspectives on embodiment and consciousness. In W. Overton, U. Mueller \& J. L. Newman (Eds.) Developmental perspectives on embodiment and consciousness (pp.1-18). New York, USA: Taylor \& Francis Group.

Rey, F. G. (2020). Methodological and epistemological demands in advancing the study of subjectivity from a cultural-historical standpoint. Culture \& Psychology, 26(3), 562-577.

Rossetti-Ferreira, M. C., Amorim, K. S., \& Silva, A. P. S. (2007). Network of meanings: A theoretical-methodological perspective for the investigation of human developmental processes. In J. Valsiner \& A. Rosa (Eds.), The Cambridge handbook of sociocultural psychology (1st ed., pp. 277-290). Cambridge, UK: The Cambridge University Press.

Rossetti-Ferreira, M. C., Oliveira, Z. M. R., Campos-de-Carvalho, M., \& Amorim, K. S. (2010). Peer relations in Brazilian daycare centres: A new focus for early childhood education. In M. Kernan \& E. Singer (Eds.), Peer relationships in early childhood education and care (1st ed., pp. 88-101). London: Routledge.

Rossetti-Ferreira, M. C., Ramon, F., \& Barreto, A. R. (2002). Improving early child care and education in developing countries. In L. Backman \& C. V. Hofsten (Eds.), Psychology at the turn of the millennium (2nd ed., pp. 101-132). Hove, East Sussex: Psychology Press.

Rutanen, N. (2012). Socio-spatial practices in a Finnish daycare group for one-to three-year-olds. Early Years, 32(2), 201-214.

Silva, E. D. B. T., \& Neves, V. F. A. (2020). Os estudos sobre a educação de bebês no Brasil. Educação Unisinos, 24(1), 1-19.

Tiriba, L., \& Barros, M. I. A. (2018). Desemparedamento da infância: A escola como lugar de encontro com a natureza (2nd ed.). Rio de Janeiro, Brazil: Alana.

Vygotsky, L. S. (2010). A questão do meio na pedologia (The problem of the environment) (M. P. Vinha, Trans.). Psicologia USP, 21(4).

Wallon, H. (1942). De l'acte à la pensée:essai de psychologie comparée. Flammarion.

Wallon, H. (1981). O jogo. In A evolução psicologia da criança (pp. 75-79). Lisboa, Portugal: Estampa.

Werebe, M. J. G., \& Nadel-Brulfert, J. (1986). Henri Wallon. São Paulo, Brazil: Ática.

Yin, R. K. (2009). Case study research: Design and methods (4th ed.). London: Sage.

Open Access This chapter is licensed under the terms of the Creative Commons Attribution 4.0 International License (http://creativecommons.org/licenses/by/4.0/), which permits use, sharing, adaptation, distribution and reproduction in any medium or format, as long as you give appropriate credit to the original author(s) and the source, provide a link to the Creative Commons license and indicate if changes were made.

The images or other third party material in this chapter are included in the chapter's Creative Commons license, unless indicated otherwise in a credit line to the material. If material is not included in the chapter's Creative Commons license and your intended use is not permitted by statutory regulation or exceeds the permitted use, you will need to obtain permission directly from the copyright holder.

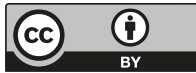

